Trinity University

Digital Commons @ Trinity

Chemistry Faculty Research

Chemistry Department

$4-2004$

\title{
Developmental Changes in Pedunculopontine Nucleus (PPN) Neurons
}

T. Kobayashi

C. Good

J. Biedermann

Christina B. Cooley

Trinity University, ccooley@trinity.edu

R. D. Skinner

See next page for additional authors

Follow this and additional works at: https://digitalcommons.trinity.edu/chem_faculty

Part of the Chemistry Commons

\section{Repository Citation}

Kobayashi, T., Good, C., Biedermann, J., Barnes, C., Skinner, R.D., \& García-Rill, E. (2004). Developmental changes in pedunculopontine nucleus (PPN) neurons. Journal of Neurophysiology, 91(4), 1470-1481. doi:10.1152/jn.01024.2003

This Article is brought to you for free and open access by the Chemistry Department at Digital Commons @ Trinity. It has been accepted for inclusion in Chemistry Faculty Research by an authorized administrator of Digital Commons @ Trinity. For more information, please contact 
Authors

T. Kobayashi, C. Good, J. Biedermann, Christina B. Cooley, R. D. Skinner, and E. E. García-Rill 


\title{
Developmental Changes in Pedunculopontine Nucleus (PPN) Neurons
}

\author{
T. Kobayashi, C. Good, J. Biedermann, C. Barnes, R. D. Skinner, and E. Garcia-Rill \\ Center for Translational Neuroscience, Department of Anatomy and Neurobiology, University of Arkansas for Medical Sciences, \\ Little Rock, Arkansas 72205
}

Submitted 22 October 2003; accepted in final form 17 November 2003

\begin{abstract}
Kobayashi, T., C. Good, J. Biedermann, C. Barnes, R. D. Skinner, and E. Garcia-Rill. Developmental changes in pedunculopontine nucleus (PPN) neurons. J Neurophysiol 91: 1470-1481, 2004; 10.1152/jn.01024.2003. The developmental decrease in rapid-eyemovement (REM) sleep in man occurs between birth and after puberty. We hypothesize that if this decrease in REM sleep does not occur, lifelong increases in REM sleep drive may ensue. Such disorders are characterized by hypervigilance and sensory-gating deficits, such as are present in postpubertal onset disorders like schizophrenia, panic attacks (a form of anxiety disorder), and depression. The decrease in REM sleep in the rat occurs between 10 and 30 days of age. We studied changes in size and physiological properties of pedunculopontine nucleus (PPN) cells involved in the control of arousal, i.e., waking and REM sleep. During the largest decrease in REM sleep (12-21 days), cholinergic PPN neurons doubled in cell area, the hypertrophy peaking at 15-16 days, then decreasing in area by $20-21$ days. Noncholinergic PPN cells did not change in area during this period. We confirmed the presence of two populations of PPN neurons based on action potential (AP) duration, with the proportion of shortAP-duration cells increasing and long AP duration decreasing between 12 and 21 days. Most cholinergic and noncholinergic cells had short AP durations. Afterhyperpolarization (AHP) duration became segregated into long and short AHP duration after 15 days. Cells with short AP duration also had short AHP duration. The proportion of PPN cells with $I_{\mathrm{h}}$ current increased gradually, peaking at 15 days, then decreased by 21 days. These changes in morphological and physiological properties are discussed in relation to the developmental decrease in REM sleep.
\end{abstract}

\section{N T R O D U C T I O N}

The human newborn exhibits an even distribution of waking, rapid-eye-movement (REM) sleep and slow-wave sleep (SWS), spending $\sim 8 \mathrm{~h}$ in each state, a process controlled by the mesopontine reticular-activating system (RAS). There follows a gradual decrease in REM sleep from $\sim 8 \mathrm{~h}$ at birth to $\sim 1$ $\mathrm{h}$ by $20 \mathrm{yr}$ of age, beyond which there is a mild decrease until senescence (Roffwarg et al. 1966). It has been suggested that REM sleep has the biological function of serving to direct the course of brain maturation (Marks et al. 1995). This is in keeping with evidence suggesting that activity-dependent development may be a widespread mechanism directing neural connectivity throughout the brain (Llinas 1984; Marks et al. 1995). High-frequency mesopontine activation, especially in the form of ponto-geniculo-occipital (PGO) waves, could contribute to the maturation of ascending RAS-induced activation of thalamocortical pathways (Marks et al. 1995). A similar effect could be in place in terms of descending RAS projections, given

Address for reprint requests and other correspondence: E. Garcia-Rill, Center for Translational Neuroscience, Dept. of Anatomy and Neurobiology, College of Medicine, University of Arkansas for Medical Sciences, $4301 \mathrm{~W}$ Markham St., Slot 510, Little Rock, AR 72205. recent results suggesting that spontaneous muscle twitches during sleep help guide spinal self-organization (Petersson et al. 2003). We hypothesized that if this developmental decrease in REM drive does not occur by the end of puberty, lifelong increases in REM sleep drive may ensue (Garcia-Rill et al. 2003). That is, such a mechanism may be responsible for the postpubertal onset in humans of a number of disorders marked by increased REM sleep drive, including schizophrenia, anxiety disorder, and (bipolar) depression (Garcia-Rill 1997).

In the rat, the developmental decrease in REM sleep occurs between 10 and 30 days of age, declining from $>70 \%$ of total sleep time at birth to $\sim 15 \%$ of sleep time by 30 days of age (Jouvet-Mounier et al. 1970). The pedunculopontine nucleus (PPN), as the cholinergic arm of the RAS, is known to modulate waking, REM sleep, and PGO waves. PPN neurons, which can be cholinergic or noncholinergic, increase their firing rates during synchronization of fast rhythms in waking and in REM sleep (i.e., show tonic activity in waking, bursting activity during REM sleep, and reduced activity during slow wave sleep) (Sakai et al. 1990; Steriade et al. 1990a,b, 1996). Steriade has described at least six different types of PGO wave-related neurons in the region of the PPN (Steriade et al. 1990a). The presence of "REM-on," "REM-off," and "WakeREM-on" cells in the region of the PPN (although these have not been identified as cholinergic or noncholinergic) also has been reported (see review by Datta 1995; and activity patterns across the sleep-wake cycle in rats in Datta and Siwek 2002).

Morphologically, PPN neurons change markedly from birth to 30 days of age in the rat. Mean cell area increased from $\sim 200 \mu \mathrm{m}^{2}$ at 10 days of age, to $>600 \mu \mathrm{m}^{2}$ at $\sim 15$ days, then decreased to the adult area of $\sim 300 \mu \mathrm{m}^{2}$ by 30 days of age (Skinner et al. 1989). The hypertrophy observed was ascribed to developmental hallmarks related to the time of eye and ear opening at $\sim 15$ days of age in the rat (Kungel et al. 1996; Sheets et al. 1988). This phenomenon was accompanied by increased labeling attributed to changes in the production of structural proteins and of enzymes involved in metabolic events, axonal growth, and synaptogenesis $\sim 15$ days of age. The subsequent decrease in mean cell size did not appear to be due to selective loss of large cells but rather to overall cell shrinkage (Skinner et al. 1989). A recent report described an increase in choline acetyltransferase activity during the developmental decrease in REM sleep percent in the rat (Ninomiya et al. 2001), simultaneously with the hypertrophy described previously.

We have been studying the changes in PPN neuronal properties, synaptic inputs, and neurochemical control during the

\footnotetext{
The costs of publication of this article were defrayed in part by the payment of page charges. The article must therefore be hereby marked "advertisement" in accordance with 18 U.S.C. Section 1734 solely to indicate this fact.
} 
most rapid decrease in REM sleep in the rat, 12-21 days postnatally. This work in brain stem slices has revealed important principles that may apply to developmental regulation of arousal and sleep-wake cycles at the cellular level. For example, we recently described the presence of a decrease in $N$ methyl-D-aspartic acid (NMDA) responses in intracellularly recorded PPN neurons during this period with a concomitant increase in kainic acid (KA) responses over the same time (Kobayashi et al. 2004). The shift from NMDA to KA predominance occurred at $\sim 15$ days. Between 12 and 21 days, we also found gradually increasing inhibitory responses to a serotonergic (5-HT) type 1 receptor agonist in PPN neurons (Kobayashi et al. 2003). The present findings describe morphometric and electrophysiological changes during this period in development in PPN neurons identified as cholinergic or noncholinergic. The changes observed over the developmental decrease in REM sleep may be of considerable clinical importance given the critical nature of this period in development and the hypothesis outlined in the preceding text.

\section{METHODS}

\section{Subjects}

Timed-pregnant Sprague-Dawley rats (280-350 g) were used, and the litters were culled to 10 . At 12-21 days of age, pups were anesthetized using ketamine $(70 \mathrm{mg} / \mathrm{kg} \mathrm{im})$ until tail pinch and corneal reflexes were absent and were rapidly decapitated. The brains were dissected free under cooled $\left(4^{\circ} \mathrm{C}\right)$, oxygenated $\left(95 \% \mathrm{O}_{2}-5 \% \mathrm{CO}_{2}\right)$ artificial cerebrospinal fluid (ACSF), and semi-horizontal brain stem slices were cut along the long axis of the PPN for recording of developmental changes in local properties. The block of tissue was glued onto a stage and $400 \mu \mathrm{m}$ slices cut with a Vibroslicer (Campden Instruments) under cooled, oxygenated ACSF, and then allowed to equilibrate for $1 \mathrm{~h}$ in oxygenated ACSF at room temperature before recording. The composition of the ACSF was (in $\mathrm{mM}$ ) $122.8 \mathrm{NaCl}, 5$ $\mathrm{KCl}, 1.2 \mathrm{MgSO}_{4}, 2.5 \mathrm{CaCl}_{2}, 1.2 \mathrm{NaH}_{2} \mathrm{PO}_{4}, 25 \mathrm{NaHCO}_{3}$, and 10 dextrose. Only $1-2$ of the $400-\mu \mathrm{m}$ slices from each brain contained the PPN. We used 150 pups to generate the data described herein. All animal use procedures were approved by the Institutional Animal Care and Use Committee.

\section{Recording procedures}

The recording chamber allowed the slice to be suspended on a nylon mesh so that oxygenated ACSF could flow evenly around the slice. The gravity-fed ACSF flowed through a sleeve of circulating warmed water so that the temperature of the ACSF in the chamber was $30 \pm 1{ }^{\circ} \mathrm{C}$ (mean $\pm \mathrm{SD}$ ). The outflow was removed by suction and the flow adjusted to $2-3 \mathrm{ml} / \mathrm{min}$. Microelectrodes were pulled in a Sutter Instruments puller using Omega-Dot, thin-wall borosilicate glass and filled with $3 \mathrm{M} \mathrm{K}^{+}$acetate and $1 \%$ biocytin and had a resistance of 70-90 M $\Omega$. Signals were amplified with an Axoclamp 2B amplifier (Axon Instruments, Foster City, CA) in current-clamp mode. Neurons were impaled and allowed to stabilize for $\sim 5 \mathrm{~min}$ before testing. Neurons that showed a stable resting membrane potential (RMP) up to $-50 \mathrm{mV}$ and action potentials $\geq 45 \mathrm{mV}$ and that had stable, long-term recordings were accepted for data analysis. The RMPs were verified and adjusted when the electrode was withdrawn at the end of recordings (usually only 1-2 $\mathrm{mV}$ difference, sometimes $>5 \mathrm{mV}$ especially after biocytin injection). In bridge mode, a series of hyperpolarizing and depolarizing current steps of $0.1-1.0 \mathrm{nA}$ at RMP were applied to determine membrane properties. These current steps also allowed the computation of a preliminary $I-V$ curve during the linear range of voltage deflections using SuperScope software (GW Instruments).

\section{Stimulation procedures}

Neuroactive agents could be applied via a manifold with perfusion ports, hence multiple gravity-fed solutions could be applied for pharmacological characterization of neuronal properties. The agents superfused in these studies were the $I_{\mathrm{h}}$ current blocker ZD7288 (Chevaleyre and Castillo 2002; Luthi et al. 1998), at a concentration of 10 $\mu \mathrm{M}$, and the sodium channel blocker tetrodotoxin (TTX), at a concentration of $0.3 \mu \mathrm{M}$. Superfusion was performed for $1 \mathrm{~min}$, then the bath was allowed to wash out so that recovery could be assessed.

\section{Physiological identification}

The presence of three types of PPN neurons was reported in the guinea pig, namely neurons with a low-threshold spike (LTS; type 1), an A current (type 2), and both A+LTS (type 3) (Leonard and Llinas 1990). Most type 2 and 3 neurons were identified as cholinergic. It should be noted that even newborn guinea pigs show adult-like REM sleep percent, so that their REM sleep drive is more like that of the adult rat, and they undergo no major changes in sleep/wake control across postnatal development (Jouvet-Mounier et al. 1970). As far as the rat is concerned, there appears to be agreement across laboratories that there are three types of PPN neurons, type I (LTS, noncholinergic), type II (A, 2/3 cholinergic) and type III (A+LTS, 1/3 cholinergic) (Kamondi et al. 1992; Kang and Kitai 1990; Leonard and Llinas 1990; Takakusaki and Kitai 1997; Takakusaki et al. 1997). Therefore we first determined electrophysiologically the type of PPN neuron being studied, injected it intracellularly, and later confirmed whether it was cholinergic or not.

\section{Anatomical identification}

At the end of the recording period, each neuron was injected with biocytin using intracellular depolarizing pulses adjusted to elicit a train of action potentials $(0.5-1.0 \mathrm{nA})$ of $500-\mathrm{ms}$ duration at $1 \mathrm{~Hz}$ for 10-15 min. Such injections yielded well-filled neurons. All of the slices were first processed for Texas Red-avidin immunocytochemistry (for viewing using fluorescence microscopy) by incubating the slices in Texas Red-avidin for $3 \mathrm{~h}$, and then processed for NADPH diaphorase histochemistry (for viewing using light microscopy) for selective labeling of cholinergic mesopontine (PPN) neurons (Vincent et al. 1983). Briefly, slices were fixed in $4 \%$ buffered paraformaldehyde for 1-2 h, cryoprotected in 20\% sucrose, and cut in a cryostat at $50 \mu \mathrm{m}$. Sections were incubated in $1 \mathrm{mg} / \mathrm{ml} \mathrm{NADPH}$ and $0.1 \mathrm{mg} / \mathrm{ml}$ nitroblue tetrazolium in PBS at $37^{\circ} \mathrm{C}$ for $30-60 \mathrm{~min}$. Double-labeled neurons were assumed to be cholinergic PPN cells. Texas-Red-labeled NADPH diaphorase-negative cells were assumed to be noncholinergic PPN cells as long as they were in the vicinity of NADPH-diaphorasepositive (cholinergic PPN) cells. We used a Nikon image-analysis system with Metamorph software to measure cell areas.

\section{Statistical procedures}

For comparison of data between the different age groups and cell types in each experiment, measures were tested using one-, two-, or multifactor ANOVA to conclude whether any of the factors (e.g., age) had a significant effect on the magnitude of the measure (e.g., action potential duration) and also whether the interaction of the factors significantly affected the measure (age vs. duration). Differences were considered significant at values of $P \leq 0.05$. If a statistical significance was present, a post hoc test (Newman-Keuls) was used to compare between groups. In simple cases comparing two groups, unpaired $t$-test were used. Distributions also were compared using a $\chi^{2}$ test. Correlations were tested using a Pearson's correlation test. 

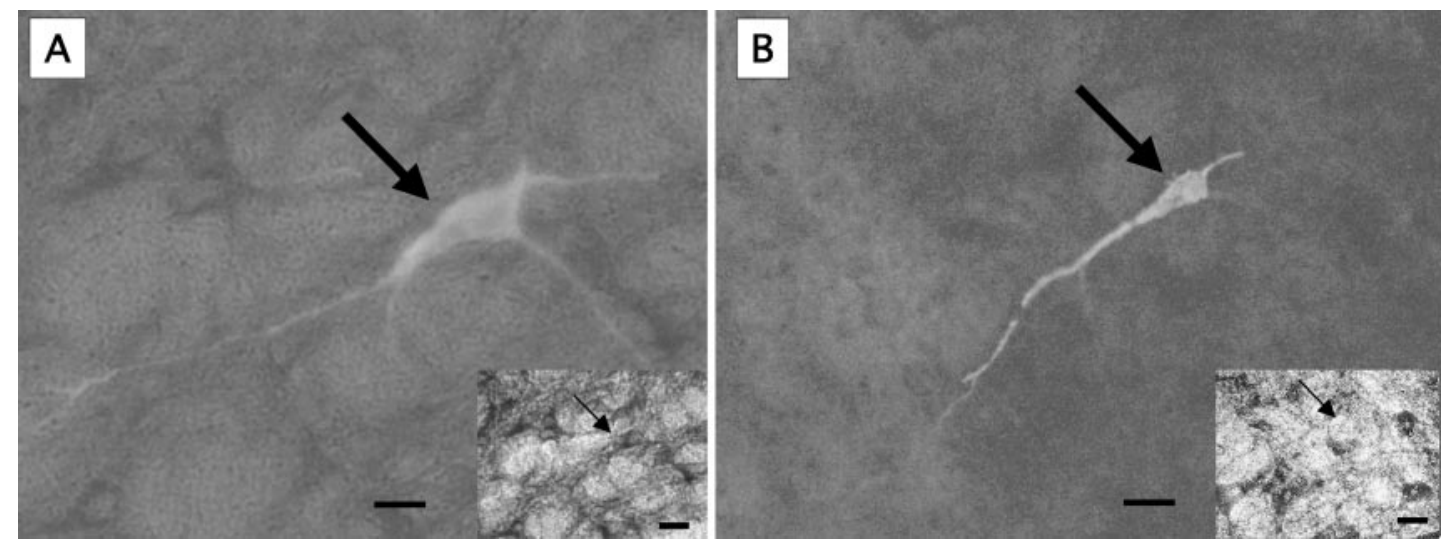

FIG. 1. Identification of intracellularly recorded pedunculopontine nucleus (PPN) neurons. A: fluorescence photomicrograph of a Texas Red-avidin-positive day 13 PPN cell and (inset) light microscopy photomicrograph of the same cell. $\rightarrow$ ( $A$ and inset) point to the same cell. Because the biocytin-injected cell $(A)$ was NADPH-diaphorase-positive (inset), it was considered a cholinergic PPN neuron. $B$ : fluorescence photomicrograph of a Texas Red-avidin-positive day 18 PPN cell and (inset) light microscopy photomicrograph of the same cell. The lack of labeling for NADPH diaphorase (inset) demonstrated that this was a noncholinergic PPN cell in the vicinity of NADPH diaphorase-positive cholinergic PPN cells. The calibration bars for the main frames are $10 \mu \mathrm{m}$, and those for the insets are $20 \mu \mathrm{m}$.

\section{RES ULTS}

\section{Mean cell area}

Figure 1 shows representative neurons recorded in these studies. In $A$, the fluorescence microscopy frame shows the Texas Red-avidin labeling of the intracellularly injected neuron, while the light microscopy inset shows the NADPH diaphorase labeling of the same neuron. This was assumed to be a cholinergic PPN neuron. In $B$, the fluorescence microscopy frame shows another Texas Red-avidin labeled (biocytin-injected) neuron, and the light microscopy frame shows that this neuron was not NADPH-diaphorase-positive, although other cells in the region were NADPH-diaphorase-positive. Therefore this neuron was assumed to be a noncholinergic PPN neuron. Of the 154 PPN cells recorded and identified for these measures, 103 cells were cholinergic and 51 were noncholinergic using these criteria.

Figure 2 is a graph of the average (mean \pm SE) cell area (in $\mu \mathrm{m}^{2}$ ) at each age of all of the neurons studied segregated into cholinergic (๑) and noncholinergic ( $\square$ ). The cholinergic PPN cell areas increased from the 12-day size of $384 \pm 20$ to a peak of $693 \pm 34 \mu \mathrm{m}^{2}$ by 15 days, before decreasing in size to $448 \pm 23 \mu \mathrm{m}^{2}$ by day 21 . Repeated-measures ANOVA and post hoc testing across age indicated that cholinergic PPN neuronal area was significantly $(\mathrm{df}=9, F=10.3, P<0.001)$ greater at 14, 15, 16, and 17 days compared with 12,20 , and 21 days. On the other hand, the noncholinergic cells recorded showed areas of $334 \pm 35 \mu^{2}$ at 12 days, $412 \pm 29 \mu \mathrm{m}^{2}$ at 15 days, and $382 \pm 19 \mu \mathrm{m}^{2}$ at 21 days. Repeated-measures ANOVA showed that there was no statistical difference $(\mathrm{df}=$ $7, F=1.27$, NS) in noncholinergic cell area across age. Fewer cholinergic and no noncholinergic cells were recorded at days 16 or 17 due to limited sampling on those days.

When one-way ANOVA was used to compare cholinergic versus noncholinergic neurons at individual ages, there was a statistically significant (range of $F$ values $=30.11-10.46, P<$ 0.001 ) increase in cell area for cholinergic neurons compared with noncholinergic cells at 13, 14, 15, 18, and 19 days.

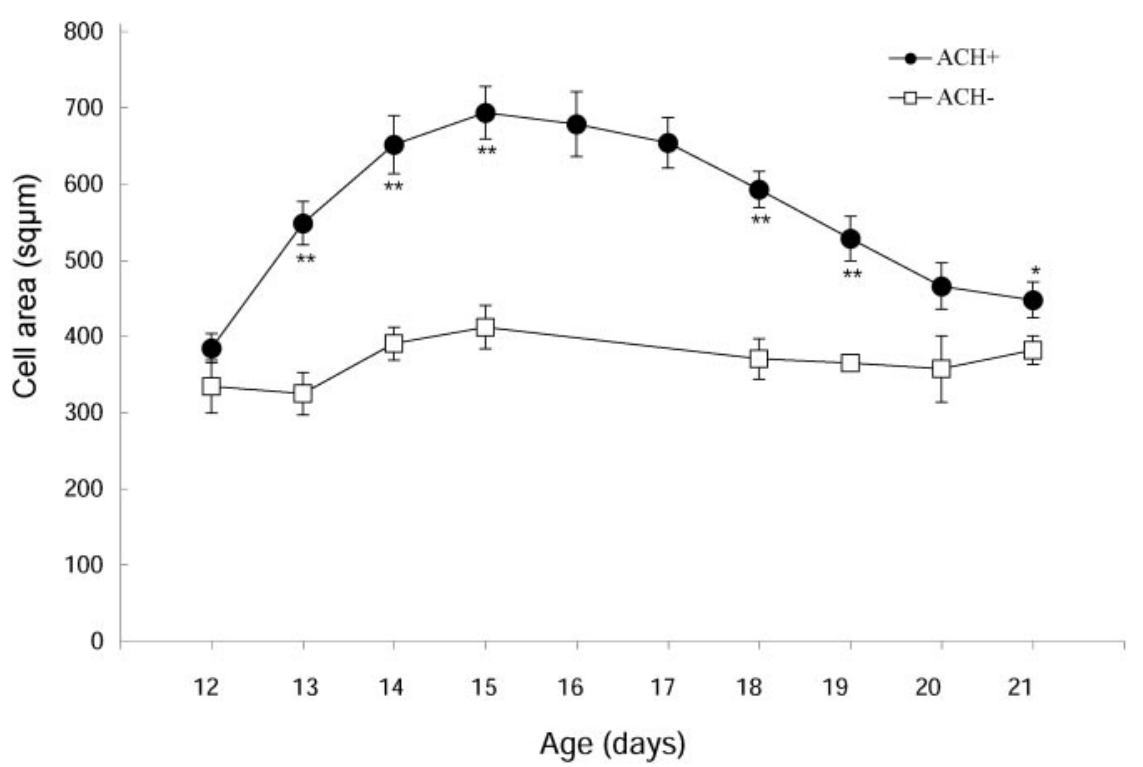

FIG. 2. Mean cell area across age for cholinergic and noncholinergic PPN neurons. $\bullet$, the mean \pm SE of the cell area of biocytin-injected, Texas Red-avidin-positive, NADPH-diaphorase-positive, i.e., cholinergic, PPN neurons at each age studied. $\square$, the mean \pm SE of the cell area of biocytin-injected, Texas Red-avidin-positive, NADPH-diaphorase-negative, i.e., noncholinergic, PPN neurons at each age studied. These means are listed in Table 2. At 12 days, the areas of cholinergic and noncholinergic cells were not statistically different but did differ statistically until day $19(* * P<0.01)$. On day 20 , they no longer differed statistically, but on day 21 , they were marginally different $(* P<0.05)$. 
However, they did not differ in mean cell area at the beginning of the period studied (12 days, $P=0.31$, NS) or toward the end (20 days, $P=0.12, \mathrm{NS}$ ). Interestingly, there was a statistically significant (although marginal) difference in cell area at 21 days with cholinergic neurons being slightly larger than noncholinergic neurons $(P=0.049)$. No comparisons could be made at 16 and 17 days.

\section{APs}

Previous studies had described the presence of two populations of type 2 (A current, 2/3 cholinergic) PPN neurons $>30$ days of age based on their action potential durations, namely 0.7-1.5 and 1.6-2.9 ms (Takakusaki and Kitai 1997). We undertook a study of action potential durations of type 2 PPN neurons across the critical period in development of 12-21 days. Table 1 lists the means \pm SE of the action potential durations of type 2 PPN neurons. As previously described, the action potential durations of these cells fell into two groups, a short- and a long-AP-duration group based on the preceding durations. When these type 2 neurons were divided into cholinergic and noncholinergic cells, we found that the overwhelming majority of cholinergic neurons had short AP duration $(58 / 60,95 \%)$ and only few had long AP duration (5\%). Most noncholinergic neurons $(21 / 26,80 \%)$ also had short AP duration compared with long AP duration (20\%).

Figure 3 is a graph of the AP durations of the short- versus long-AP-duration groups over age. In Fig. $3 A$, we plot the short- versus long-duration-AP cells by age, showing that there is no change across age in the mean duration of short versus long AP durations. Representative examples of short- versus long-duration type 2 PPN neurons are shown on the right. Note the difference in AP duration but the similarity in the presence of an $\mathrm{A}$ current in both groups. In Fig. 3B, we plot the percentage of short- versus long-AP-duration type 2 PPN neurons over age. This graph shows that although mean AP duration did not change over age, the percentage of long-APduration cells decreased over age, whereas the percentage of short-AP-duration cells increased over age. The distributions of short- versus long-AP-duration neurons over age (2-day epochs) were compared using a $\chi^{2}$ test and found to be statistically different $\left(\mathrm{df}=4, \chi^{2}=42.1, P<0.001\right)$.

A final analysis on the AP in these neurons was the mean firing frequency induced by depolarizing steps in short- versus long-AP-duration neurons. Depolarizing steps of $+0.5 \mathrm{nA}$ induced a mean firing frequency of $32.4 \pm 3.9 \mathrm{~Hz}$ in shortAP-duration cells, but a statistically (unpaired $t$-test, df $=64$, $t=-2.44, P<0.02$ ) lower firing frequency of $24.0 \pm 1.3 \mathrm{~Hz}$ in long-AP-duration cells. Depolarizing steps of $+0.9 \mathrm{nA}$ induced a firing frequency of $39.6 \pm 5.9 \mathrm{~Hz}$ in short-APduration cells and $43.5 \pm 2.9 \mathrm{~Hz}$ in long-AP-duration cells, but

TABLE 1. AP durations over age

\begin{tabular}{lcccc}
\hline \hline Age, day & Number & Short AP, ms & Number & Long AP, ms \\
\hline $12-13$ & 7 & $1.05 \pm 0.13(29)$ & 17 & $2.36 \pm 0.16(71)$ \\
$14-15$ & 6 & $0.81 \pm 0.15(30)$ & 14 & $2.47 \pm 0.14(70)$ \\
$16-17$ & 6 & $0.90 \pm 0.13(50)$ & 6 & $2.69 \pm 0.14(50)$ \\
$18-19$ & 10 & $0.91 \pm 0.11(67)$ & 5 & $2.20 \pm 0.11(33)$ \\
$20-21$ & 11 & $0.70 \pm 0.10(58)$ & 8 & $2.10 \pm 0.11(42)$ \\
\hline
\end{tabular}

Values are means \pm SE. Percentages are in parentheses. the difference was not statistically significant (unpaired $t$-test, $\mathrm{df}=30, t=0.43$, NS).

\section{AHP}

The distribution of mean AHP durations over age was stable but with a great deal of variability (Fig. 4). For example, the mean AHP duration in 12- to 15-day cells versus 16- to 21-day cells was not statistically different, but there appeared to be a segregation of AHP duration into two populations. When cholinergic and noncholinergic cells together were considered, PPN neurons aged 16-21 days had either long AHP duration $(239 \pm 6 \mathrm{~ms})$ or short AHP duration $(86 \pm 10 \mathrm{~ms}$; ANOVA df $=45, F=169.6, P<0.0001)$. Regression analysis of these two populations showed that the slopes of the best-fit lines describing the AHP duration had diverging slopes with age. Long-AHP-duration cells had an $r$ value of 0.89 and shortAHP-duration neurons had an $r$ value of 0.71 . That is, after day 16 , there was a gradually increasing difference in AHP duration between the two populations of type 2 cells, indicative of a marked change in potential firing rate after 15 days. We then divided these cells into cholinergic and noncholinergic neurons. Cholinergic cells $12-15$ days showed a mean AHP duration of $131 \pm 10 \mathrm{~ms}(n=40)$, whereas noncholinergic cells had an AHP duration of $129 \pm 16 \mathrm{~ms}(n=29)$, i.e., were not statistically different. Similarly, 16- to 21-day cholinergic cells had an AHP duration of $126 \pm 12 \mathrm{~ms}(n=58)$, whereas noncholinergic cells were $139 \pm 15 \mathrm{~ms}(n=19)$, again, not different.

However, Fig. $4 A$ is a graph of the individual AHP durations of cholinergic PPN cells showing the apparent segregation of these neurons into two nonoverlapping populations based on AHP duration. There were no AHP durations between 127 and $170 \mathrm{~ms}$ in 16- to 21-day cholinergic cells. We pooled these groups into $<150$ and $>150 \mathrm{~ms}$ durations. The short-AHPduration cells had an average AHP duration of $66 \pm 5 \mathrm{~ms}(n=$ $36)$ and the long-AHP-duration of $225 \pm 12 \mathrm{~ms}(n=22)$, and these were statistically different $(F=3.44, P<0.001)$. The best-fit lines showed divergent slopes (Fig. 4A). On the other hand, 16- to 21-day noncholinergic cells showed no AHP durations between 110 and $140 \mathrm{~ms}$. Arbitrarily dividing these into $<125$ - and $>125-\mathrm{ms}$ durations again revealed two populations (short AHP: $82 \pm 8 \mathrm{~ms}, n=9$; long AHP: $191 \pm 14$ ms, $n=10 ; F=3.62, P<0.001)$. However, noncholinergic PPN cells aged 16-21 days showed convergent slopes of AHP durations (Fig. 4B).

The segregation into long and short AHP duration was related to the long and short AP duration described in the preceding text. There was no correlation between AP duration and AHP duration for cells aged 12-15 days. Pearson's correlation for cells on the Fig. 4, left, showed no significant correlation between AP and AHP duration ( $\mathrm{df}=42, F=1.51$, NS). However, for cells aged 16-21 days, there was a significant correlation between AP duration and AHP duration $(\mathrm{df}=$ $45, F=12.76, P<0.001)$. Basically, for cells $16-21$ days of age, long-AHP-duration cells (239 $\pm 31 \mathrm{~ms})$ also had long AP durations $(1.8 \pm 0.8 \mathrm{~ms})$ and short-AHP-duration cells (86 \pm $47 \mathrm{~ms}$ ) also had short AP durations $(1.0 \pm 0.6 \mathrm{~ms})$. This relationship may be straightforward because a prolongation in the AP duration may allow additional calcium entry during repolarization, thus improving the likelihood of activating the 


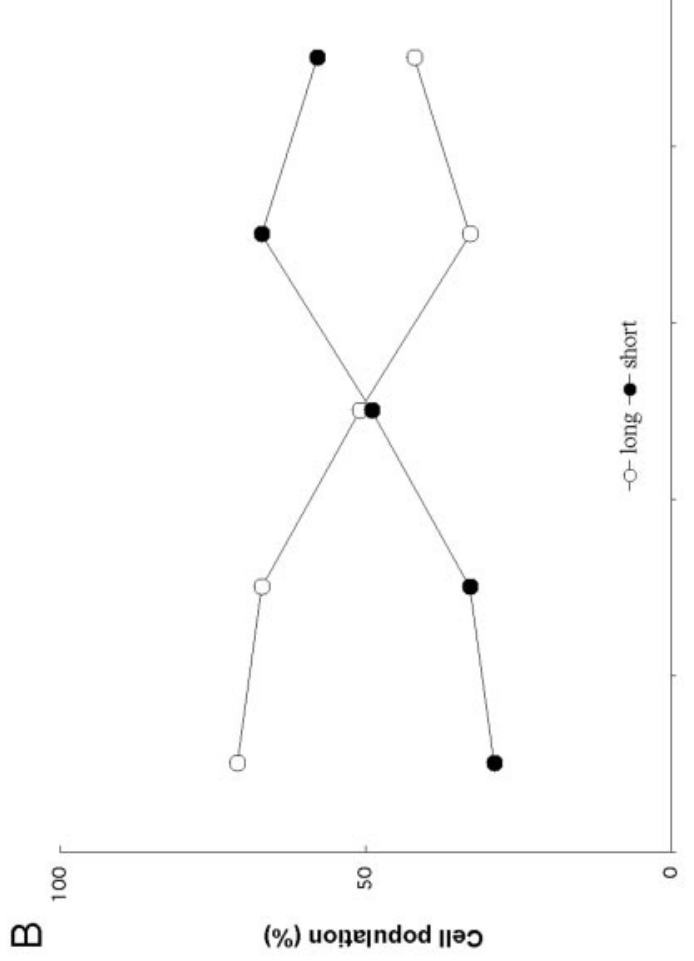

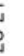

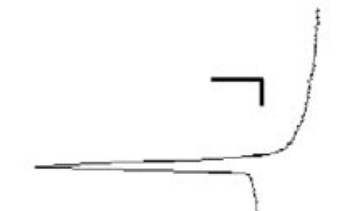

$\hat{\frac{0}{6}} \frac{\frac{\pi}{\sqrt{0}}}{\frac{g}{x}}$

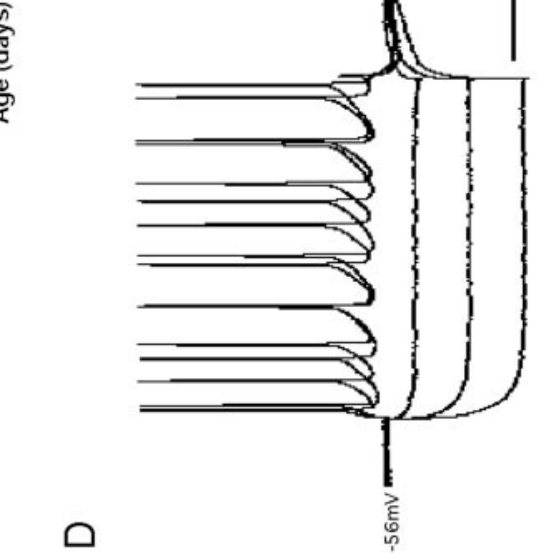

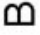

(\%) uo!̣e!ndod ॥ә弓

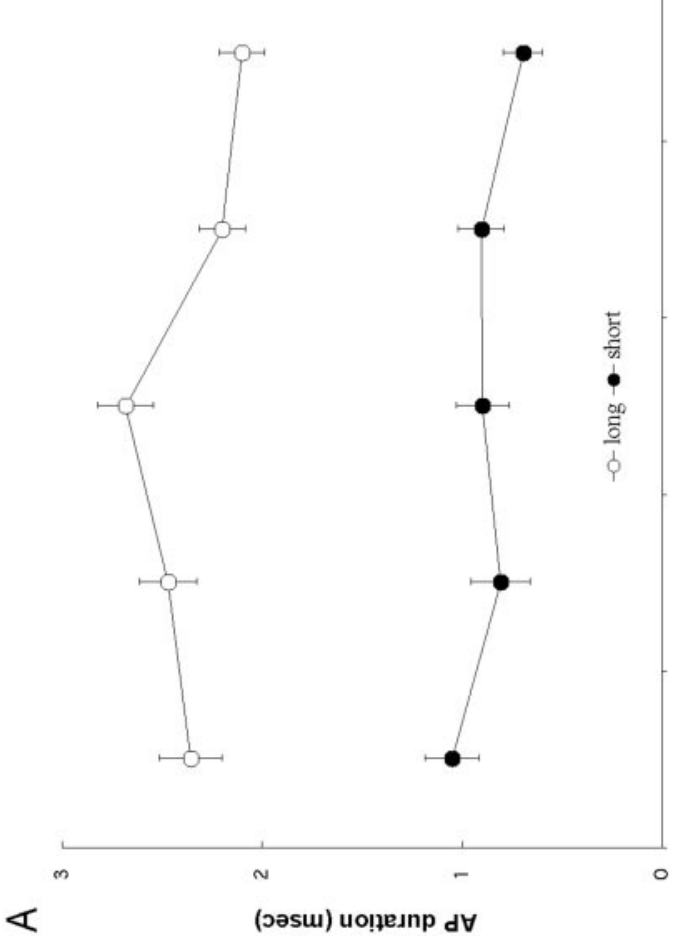

సั่

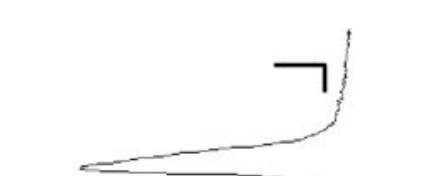

छ

띵 운 킁 중

$+1 \stackrel{5}{0} 0$

$\Xi \overline{0}: 0.0$

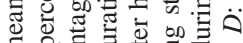

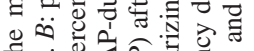

I

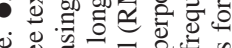

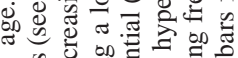

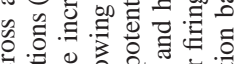

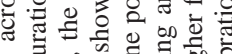

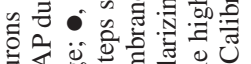

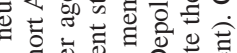

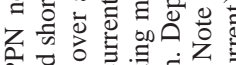

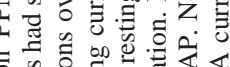

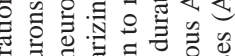

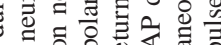

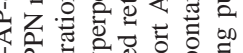

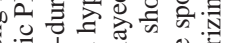

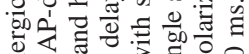

Ð

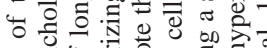

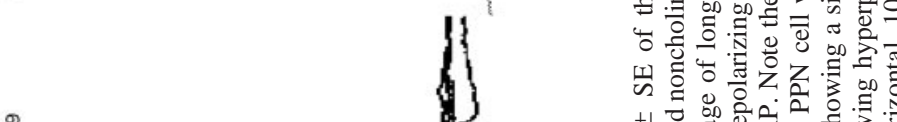

- \ل

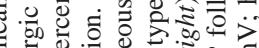

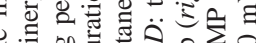

竞:
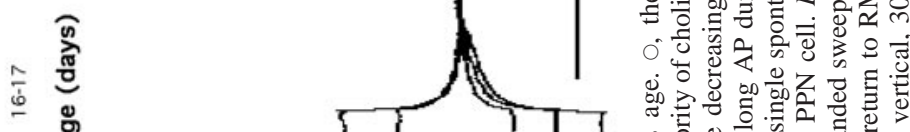

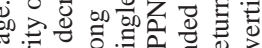

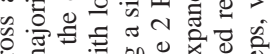

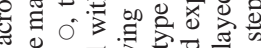

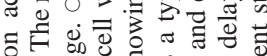

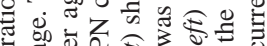

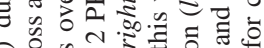

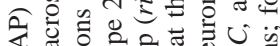

《

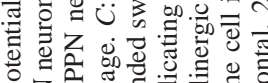

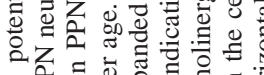

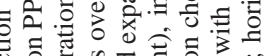

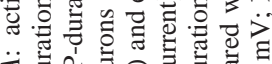

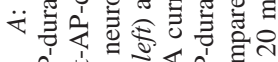

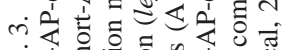

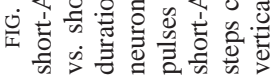



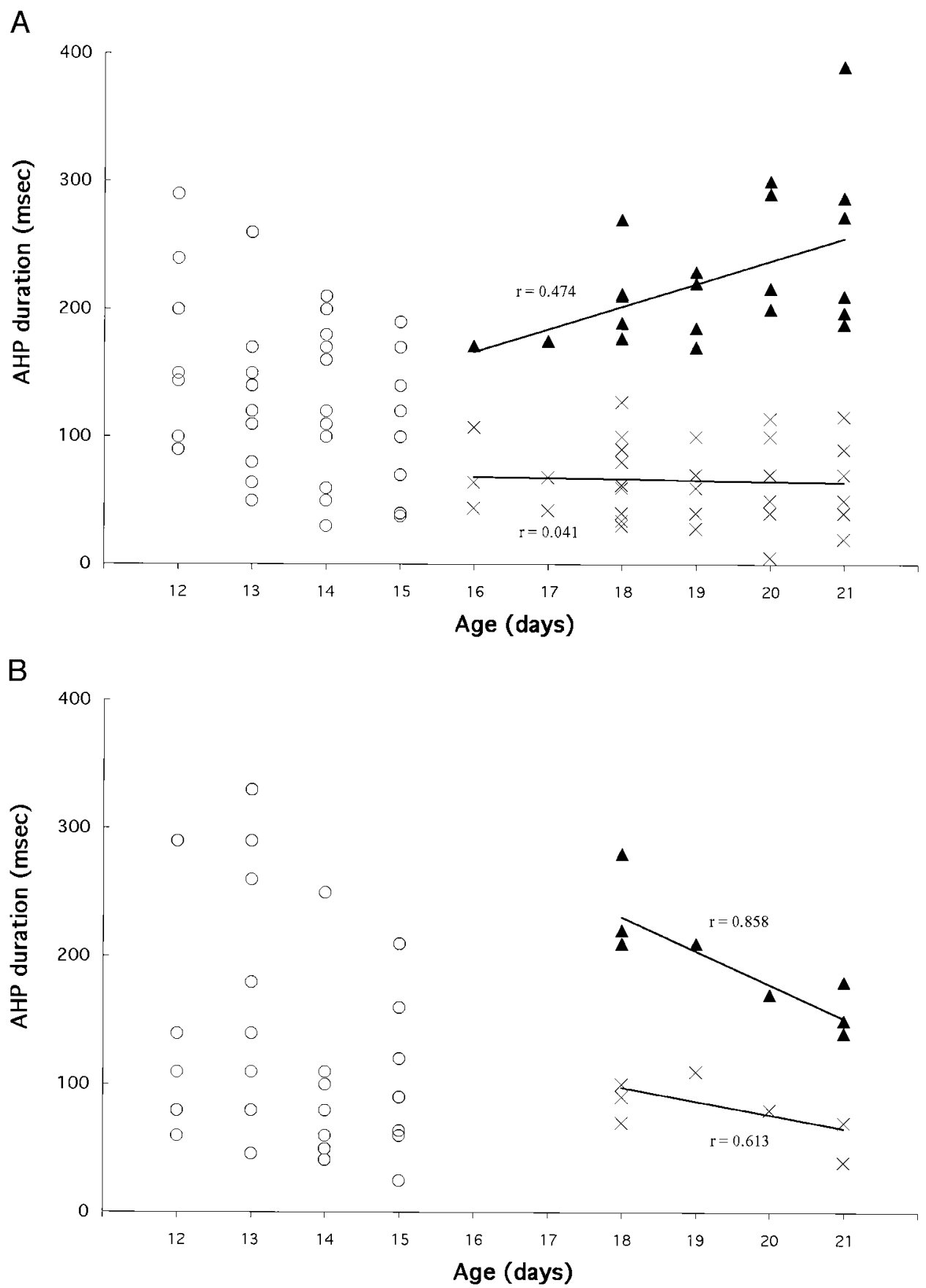

FIG. 4. Afterhyperpolarization (AHP) duration across age. A: AHP in cholinergic type 2 PPN cells. $\bigcirc$, a homogeneous distribution of AHP durations for 12-15 day cells with mean of $131 \pm 10(\mathrm{SE}) \mathrm{ms}(n=40)$ whereas the mean for 16-21 days was $126 \pm 12 \mathrm{~ms}(n=58)$. However, there appeared to be 2 discernible populations of 16- to 21-day cells. When these were pooled into AHP durations $<150 \mathrm{~ms}$ vs. those with AHP durations $>150 \mathrm{~ms}$, they were significantly different (long AHP duration: $225 \pm$ $12 \mathrm{~ms}, n=22$, vs. short AHP duration: $66 \pm$ $5 \mathrm{~ms}, n=36 ; F=3.44, P<0.01) . \times$, short-duration-AHP neurons; $\Delta$, long-duration-AHP neurons. The best fit lines for the long- vs. short-duration-AHP cells 16-21 days of age showed diverging slopes with age, indicating that there may be 2 populations of cells with increasingly different AHP durations. $B$ : AHP in noncholinergic type 2 PPN cells. $O$, a homogeneous distribution of AHP durations for 12- to 15-day cells with a mean of $129 \pm 16 \mathrm{~ms}(n=29)$, whereas the mean for 16-21 days was $139 \pm 15 \mathrm{~ms}(n=19)$. These cells were divided into short vs. long duration AHP $(\langle 125\rangle \mathrm{ms})$. While the means did show a statistically significant difference (long AHP duration: $191 \pm 14 \mathrm{~ms}, n=10$, vs. short AHP duration: $82 \pm 8 \mathrm{~ms}, n=9 ; F=3.62$, $P<0.01$ ), the best fit lines converged, indicating that there may be a convergence toward short AHP durations in noncholinergic type 2 PPN cells.

long-duration AHP mechanism. Previous studies found that a subpopulation of type 2 (A) cells can fire faster at $\sim 10 \mathrm{~Hz}$ in pacemaker fashion (Leonard and Llinas 1990). We suspect that these may include more short-AHP and -AP-duration neurons. These properties imply that the period $\sim 15$ days of age is a transition time between lower compared with higher firing rates in at least some type 2 PPN neurons.

\section{$I_{h}$ current}

$I_{\mathrm{h}}$ is a noninactivating inward cation current carried by sodium/ potassium ions with a -30 to $-50 \mathrm{mV}$ reversal potential that slowly activates during hyperpolarization. $I_{\mathrm{h}}$ channels have been postulated to contribute to the resting membrane potential (some of these channels are open at RMP) and control rhythmic firing in spontaneously active cells (McCormick and Pape 1990). These channels are regulated by cyclic nucleotides (DiFrancesco 1993), which may affect neuronal excitability and rhythmicity in CNS neurons (Pape and McCormick 1989), especially in thalamic neurons (Leresche et al. 1991; Soltesz et al. 1991). We analyzed the presence of $I_{\mathrm{h}}$ in type 2 PPN neurons over age. Figure $5 A$ shows the percentage of type 2 PPN neurons with and without $I_{\mathrm{h}}$ current. There was a gradual increase in the percentage of cells with $I_{\mathrm{h}}$ across age, with a concomitant decrease in cells without $I_{\mathrm{h}}$, from 12 through 17 days. After that time, the percentage of cells with $I_{\mathrm{h}}$ decreased and remained at that level. A number $(n=6)$ of 


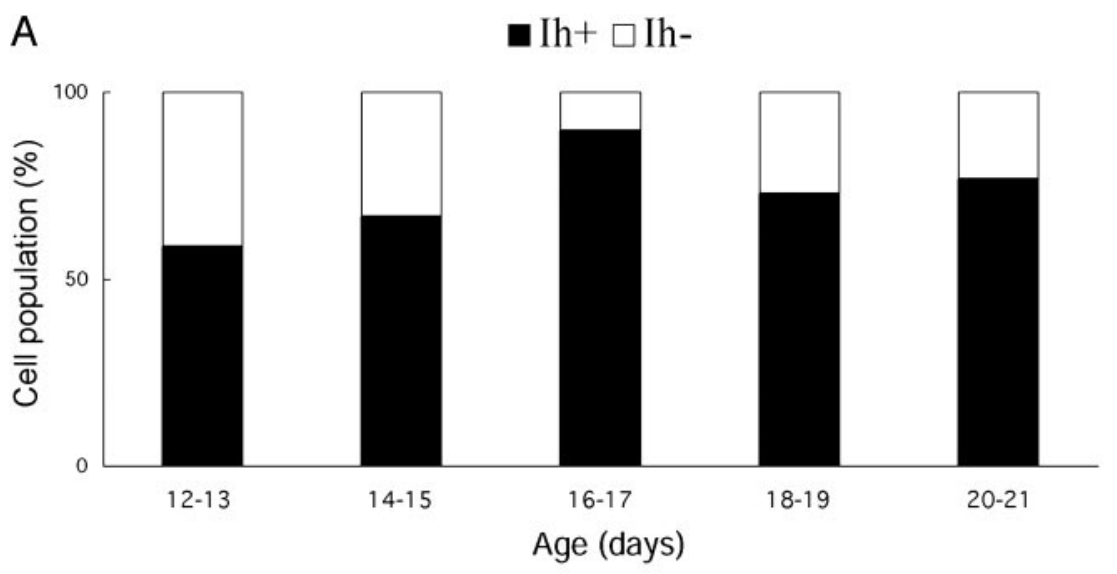

B

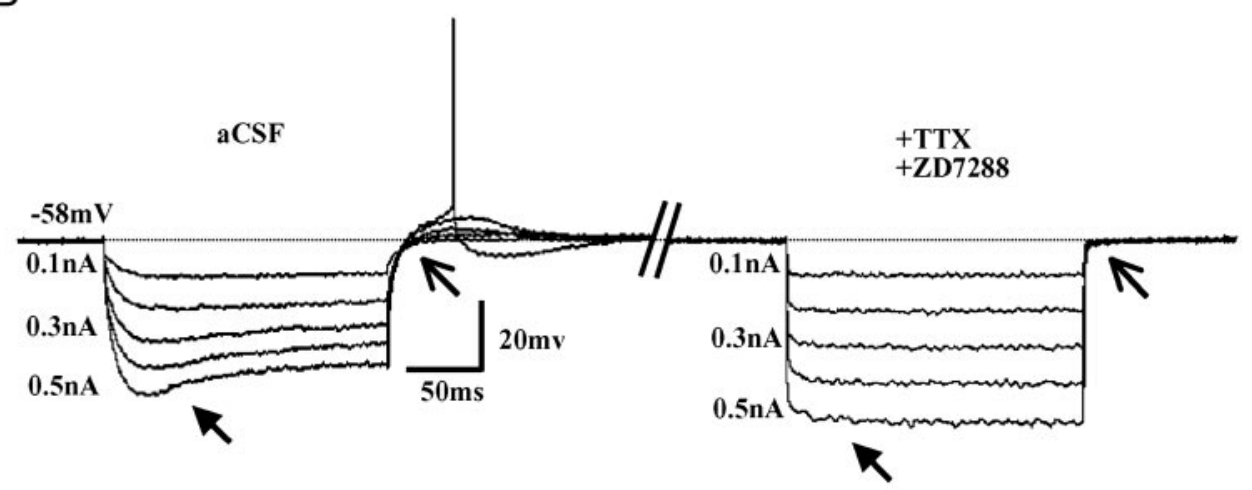

FIG. 5. $A: I_{\mathrm{h}}$ current in PPN neurons across age. The percentage of PPN neurons with $I_{\mathrm{h}}\left(I_{\mathrm{h}}+\right)$ increased gradually, peaking at 16-17 days, then decreased and stabilized by 20-21 days. Conversely, the percentage of $I_{\mathrm{h}}-$ cells decreased gradually, then increased with age. $B: I_{\mathrm{h}}+$ cholinergic PPN neuron after hyperpolarizing current steps. Left: an example of the response to current steps of $0.1-0.5 \mathrm{nA}$ in standard artificial cerebrospinal fluid. Note the presence of $I_{\mathrm{h}}$ (depolarization during the current step, closed arrowhead) and of an A current (delayed return to RMP, open arrowhead) followed by an AP, first evident at approximately $-70 \mathrm{mV}$. Right: the response of the same cell after TTX in the presence of ZD7288 $(10 \mu \mathrm{M})$ to 0.1 - to $0.5-\mathrm{nA}$ current steps. Note the absence of $I_{\mathrm{h}}$ (closed arrowhead) and of the A current (open arrowhead) along with an increase (not statistically different) in response amplitude (signifying increased resistance, closing of cation channels). Calibration bars: vertical, $20 \mathrm{mV}$; horizontal, $50 \mathrm{~ms}$. neurons were tested using the $I_{\mathrm{h}}$ blocker ZD7288, in which the current was blocked in ACSF and in the presence of TTX (Fig. $5 B$ ). As can be observed in this figure, the presence of TTX eliminated the action potential generated by the release from hyperpolarization and depolarization at the end of the A current. The $I_{\mathrm{h}}$ was blocked on addition of the blocker ZD7288; however, it should be noted that the A current was also blocked, indicating that this blocker may not be specific to $I_{\mathrm{h}}$ channels but perhaps also block other cation currents at least in PPN neurons. The amplitude of the hyperpolarizing pulses did not change after TTX exposure (not shown) but increased in amplitude after ZD7288, indicating the blockade of some current, presumably a cation current. The mean input resistance $\left(R_{\text {in }}\right)$ increased from $93 \pm 18$ $\mathrm{M} \Omega$ before to $119 \pm 24 \mathrm{M} \Omega$ after, ZD7288. This increase in $R_{\text {in }}$ was not statistically different (ANOVA df $=11, F=0.73, \mathrm{NS}$ ); however, it represented a $28 \%$ increase in resistance.

A final analysis on these neurons was the mean firing frequency induced by depolarizing steps in $I_{\mathrm{h}}$-positive versus $I_{\mathrm{h}}$-negative neurons. Depolarizing steps of $+0.5 \mathrm{nA}$ induced a mean firing frequency of $29.7 \pm 1.4 \mathrm{~Hz}$ in $I_{\mathrm{h}}$-positive cells but a statistically (unpaired $t$-test, $\mathrm{df}=130, t=-3.6, P<0.0001$ ) lower firing frequency of $20.5 \pm 2.5 \mathrm{~Hz}$ in $I_{\mathrm{h}}$-negative cells. Depolarizing steps of $+0.9 \mathrm{nA}$ induced a statistically higher (unpaired $t$-test, df $=30, t=12.5, P<0.001$ ) firing frequency in $I_{\mathrm{h}}$-positive cells $(48.6 \pm 3.4 \mathrm{~Hz})$ compared with $I_{\mathrm{h}}$-negative cells $(31.0 \pm 2.9 \mathrm{~Hz})$.

\section{Other properties}

The present studies also addressed a number of basic cell properties that did not change over age, and these are provided in Fig. 6. A group of 90 recorded neurons were pooled because there were no differences in any of the following measures between cholinergic and noncholinergic PPN neurons. Briefly, resting membrane potential (RMP) did not change in these type II neurons across the period tested $(-61.3 \pm 0.7 \mathrm{mV}), R_{\text {in }}$ likewise did not change $(116.0 \pm 5.6 \mathrm{M} \Omega$ over age, and neither did AP amplitude $(60.2 \pm 0.7 \mathrm{mV})$ or AHP amplitude $(15.5 \pm$ $0.5 \mathrm{mV})$. No trends in any of these measures were detected at the critical transition age of 15-16 days.

\section{I S C U S S I O N}

\section{Changes in cell size}

The most comprehensive previous study of developmental changes in PPN cell size was based on measurement of some 10,000 cells and was restricted to NADPH-diaphorase-labeled cells (Skinner et al. 1989). In that study, mean cell area was $391 \mu^{2}$ at 12-14 days of age, whereas our present results from intracellularly injected NADPH-diaphorase-positive cells showed a mean area of $385 \mu \mathrm{m}^{2}$ at 12 days, increasing to 549 $\mu \mathrm{m}^{2}$ at 13 days and $652 \mu \mathrm{m}^{2}$ at 14 days (Table 2). That is, cell size was similar at the beginning of the period studied, but there was a larger increase in size with age in injected cells. Similarly, the previous study showed a mean cell area to be $498 \mu \mathrm{m}^{2}$ at $15-17$ days, whereas the current study found mean area to be larger and stable at $694 \mu \mathrm{m}^{2}$ at 15 days, $679 \mu \mathrm{m}^{2}$ at 16 days, and $654 \mu \mathrm{m}^{2}$ at 17 days. Therefore while the hypertrophy during this period was evident in both studies, the cell area increase was greater in the intracellularly injected cells. While it seems logical to expect injected cells to become 
A

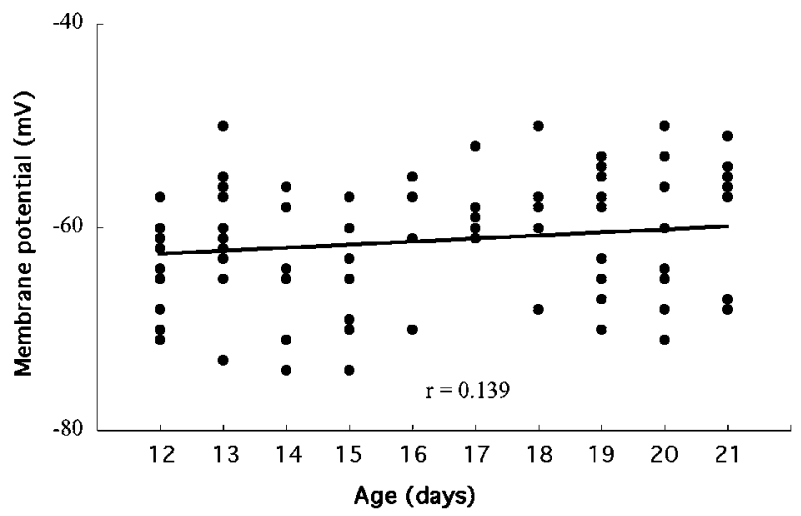

C

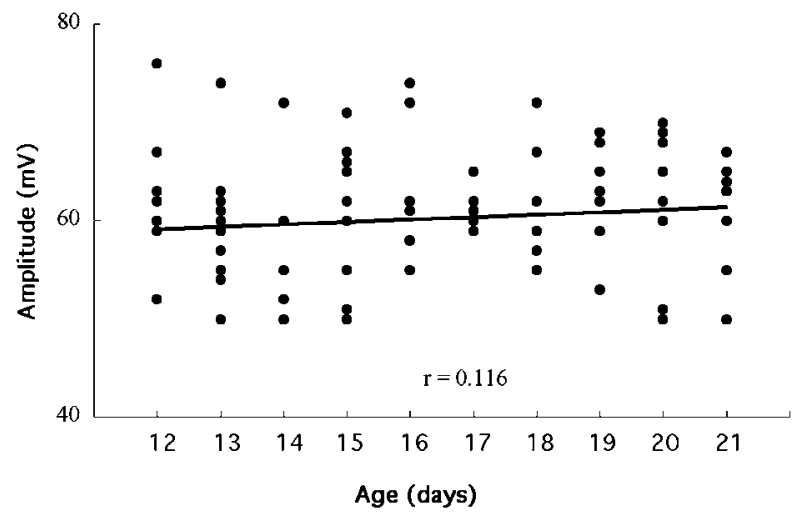

B

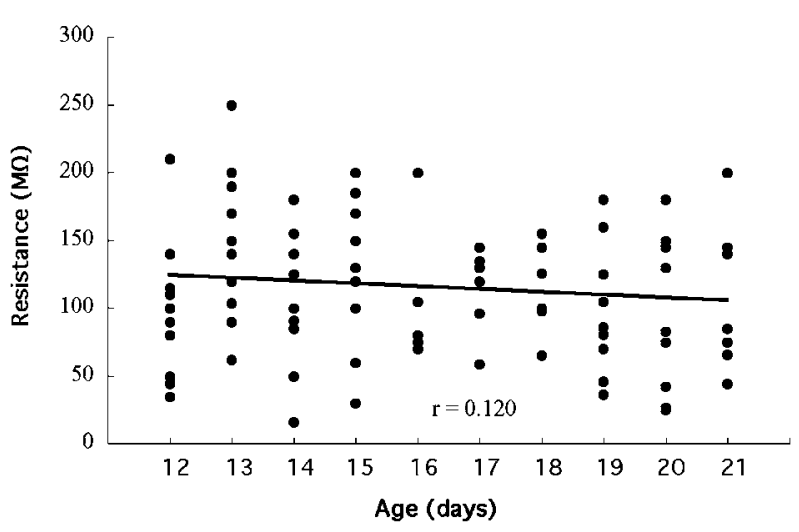

AHP amplitude

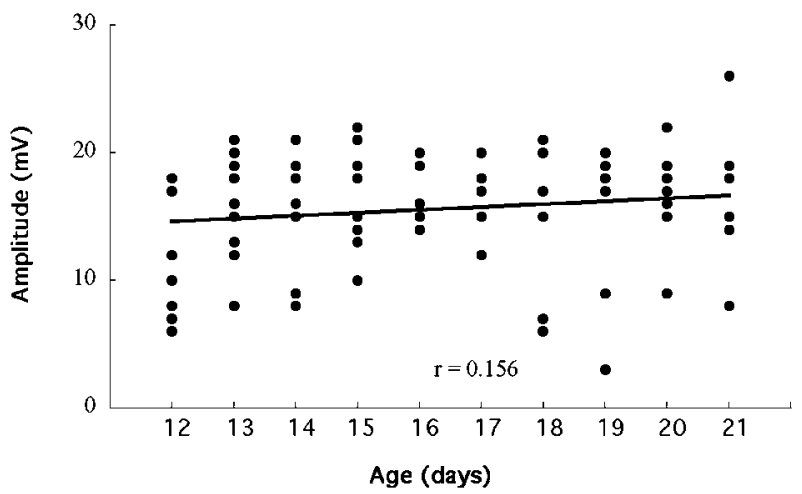

FIG. 6. Type 2 PPN cell properties across age $(n=90)$. A: RMP. RMP over age for all cells studied showed no significant changes across age. $B$ : input resistance $\left(R_{\text {in }}\right) . R_{\text {in }}$ for all of the cells studied did not show significant differences across age. $C$ : AP amplitude. AP amplitude did not show significant differences across age. D: AHP amplitude. AHP amplitude did not show significant differences across age. When each of the preceding measures were computed for cholinergic vs. noncholinergic cells, there were no statistically significant differences between cell type and basic properties.

swollen by dye injection, there was no dramatic change in cell size in intracellularly injected noncholinergic cells (Fig. 2, $\square$ ). It appears that, although the hypertrophy in cholinergic PPN neurons was evident during this period in development and mean cell area was comparable at the beginning of this epoch (12 days), the injected cholinergic cells tended to increase more in size. It is possible that the hypertrophy observed indicates a period of rapid intracellular structural flux that may

TABLE 2. Cholinergic and noncholinergic PPN mean cell area across age

\begin{tabular}{|c|c|c|c|c|c|}
\hline \multicolumn{3}{|c|}{ Cholinergic } & \multicolumn{3}{|c|}{ Noncholinergic } \\
\hline Age, day & Number & Area, $\mathrm{m}^{2}$ & Age, day & Number & Area, $\mathrm{m}^{2}$ \\
\hline 12 & 9 & $385 \pm 20$ & 12 & 5 & $334 \pm 35$ \\
\hline 13 & 12 & $549 \pm 29$ & 13 & 9 & $325 \pm 28$ \\
\hline 14 & 14 & $652 \pm 38$ & 14 & 8 & $390 \pm 22$ \\
\hline 15 & 10 & $694 \pm 34$ & 15 & 7 & $412 \pm 29$ \\
\hline 16 & 4 & $679 \pm 43$ & 16 & 0 & - \\
\hline 17 & 3 & $654 \pm 33$ & 17 & 0 & - \\
\hline 18 & 15 & $593 \pm 24$ & 18 & 8 & $371 \pm 27$ \\
\hline 19 & 11 & $529 \pm 30$ & 19 & 4 & $366 \pm 8$ \\
\hline 20 & 12 & $466 \pm 30$ & 20 & 2 & $358 \pm 44$ \\
\hline 21 & 13 & $448 \pm 23$ & 21 & 8 & $382 \pm 19$ \\
\hline
\end{tabular}

Values are means $\pm \mathrm{SE}$. have made the cells more amenable to swelling with injection than when cell size had stabilized later (after 17 days) during the period studied. Interestingly, cell area decreased to 461 $\mu \mathrm{m}^{2}$ by $21-23$ days in the previous study, whereas the current work revealed a similar mean area of $448 \mu \mathrm{m}^{2}$ at 21 days, i.e., a virtually identical regression in cell size. This suggests that injection at this age did not produce excessive swelling. Therefore at present, we cannot completely account for the larger average areas of injected cells (compared with histochemical labeling) during the peak of the hypertrophy in injected cells. Moreover, this effect was evident only in cholinergic, not noncholinergic, cells, suggesting that differences in fixation procedures and the like did not account for the difference.

Moreover, the previous study on PPN cell size employed a mathematical technique developed for skewed distributions modeled by a Weibull function (Skinner et al. 1989). This analysis determined that the hypertrophy observed at 15-17 days indicated a generalized growth followed by shrinkage of most cells and did not represent a selective loss of the largest cells. Our current sample size does not permit us to carry out such an analysis, but we assume that the same principles apply, i.e., the decrement in area by 21 days is due to overall size shrinkage not selective loss of large cells.

The hypertrophy, as stated in the preceding text, was limited 
to cholinergic cells, whereas noncholinergic neurons did not change significantly in size across this period. At 21 days, however, cholinergic cells did show a marginally greater mean cell area compared with noncholinergic cells. This difference was statistically significant, perhaps because of the lower (than at other ages) variance in each of the populations at 21 days. Previous studies on adult or juvenile rats have shown that there is no major difference in cell size between cholinergic and noncholinergic PPN neurons (Spann and Grofova 1992) or between intracellularly studied type 2 cholinergic and noncholinergic PPN cells (Takakusaki et al. 1996). Our results also suggest that, after 19 days, any differences between these neurons in terms of area will be minor.

Why is there a selective hypertrophy of PPN cholinergic neurons around 15 days? The marked changes in cell area could be related to developmental highlights marking eye and ear opening coupled with increased sensory input (Kungel et al. 1996; Sheets et al. 1988). However, the hypertrophy is exclusively in cholinergic neurons, suggesting that a transient yet specific change in cholinergic cell size is present in the PPN at this time. A transient increase in neuronal cell size in the second and third postnatal weeks has been reported in the neighboring locus coeruleus (Shimizu and Imamoto 1970; Sievers et al. 1981). This phenomenon was attributed to changes in the production of structural proteins and of enzymes involved in metabolic events. The increased NADPH diaphorase labeling previously observed in PPN cells was ascribed to similar processes (Skinner et al. 1989). However, these metabolic events may be more related to output functions such as axonal growth and synaptogenesis, rather than to changes in inputs to PPN neurons, as the discussion in the following text will propose.

\section{Changes in cell properties}

The presence of short- and long-AP-duration PPN neurons has been described previously (Takakusaki and Kitai 1997), but the fact that there is a developmental shift toward a greater proportion of short AP durations at $\sim 15$ days of age is novel. Most cholinergic and noncholinergic PPN neurons exhibited this shift. This suggests that AP duration detected extracellularly should not be used as a method for identifying cholinergic versus noncholinergic PPN cells. In addition, our results show a segregation of AHP durations after 15 days into short- and long-AHP-duration populations but only in cholinergic cells. From a functional viewpoint, longer-duration AHPs would be expected to lead to decreasing firing rates in cholinergic neurons, which may contribute to a decrease in REM sleep duration. Such a decrement in firing rate would be less significant in noncholinergic neurons because they showed a trend toward decreasing AHP duration. Taken at face value (and considering the relatively small sample size), a tentative conclusion may be that cholinergic neurons contribute more to the decrement in REM sleep duration than noncholinergic neurons.

Significantly, the populations of short-AP- and short-AHPduration neurons were correlated, suggesting that, after 15 days, there is a gradual trend toward a large population of cholinergic and noncholinergic PPN neurons that have faster firing properties. This relationship may be straightforward because a prolongation in the AP duration may allow additional calcium entry during repolarization, thus improving the likeli- hood of activating the long-duration-AHP mechanism. The fact that cells with short AP duration also had short AHP duration is a generalized finding evident in cortical neurons during natural sleep-wake states (Steriade et al. 2001). Previous studies found that a subpopulation of type 2 (A) PPN cells can fire faster at $\sim 10 \mathrm{~Hz}$ in pacemaker fashion (Leonard and Llinas 1990), a manifestation evident during natural sleep-waking states (Steriade et al. 1990b). We suspect that these may include more short-AP- and -AHP-duration neurons. These properties imply that the period $\sim 15$ days of age is a transition time between lower compared with higher firing rates in at least some type 2 PPN neurons. Interestingly, however, these changes in AP and AHP duration gradually increased or decreased but did not show an inverted $U$ distribution as did cell area.

The most common excitatory transmitter in the PPN is glutamate. Recent studies have revealed that injection of glutamate into the PPN increased both waking and REM sleep in freely moving rats (Datta 2002). Injections of NMDA induced a selective increase in waking, whereas injections of kainic acid induced a selective increase in REM sleep. We reported that the depolarization induced by NMDA on cholinergic PPN neurons gradually decreased between 12 and 21 days, whereas the depolarization induced by kainic acid on these neurons gradually increased over the same period (Kobayashi et al. 2004). The shift from NMDA to kainic acid regulation occurred at $\sim 15$ days. These data imply that the control of REM sleep comes under the predominant influence of kainate receptors. It is unclear if the gradually increasing capacity for faster firing in cholinergic PPN neurons discussed in the preceding text is directly related to the gradually increasing kainic acid modulation of these cells over the same time period. Additional research will be needed to establish a functional link between these events.

$I_{\mathrm{h}}$ currents are generated by hyperpolarization-activated, cyclic nucleotide-gated channels (HCNs), and the channel proteins are encoded by at least four HCN genes (HCN1-HCN4) (see a recent review by Santoro and Baram 2003). The four homomeric channels differ such that activation and deactivation is fastest for HCN1 and slowest for HCN4. HCN1 is found mainly in cortex, whereas HCN4 is found subcortically. We assume that PPN neurons have at least some HCN4 channels, although this needs to be confirmed using, for example, in situ hybridization. Interestingly, $I_{\mathrm{h}}$ proteins in the hippocampus, the most studied structure, are differentially regulated during development (Bender et al. 2001; Vasilyev and Barish 2002). Originally, HCNs were thought to regulate rhythmic activity (Santoro and Baram 2003). These proteins are in turn regulated by neuronal, especially paroxysmal, activity in the hippocampus (Brewster et al. 2002) and may contribute to paroxysmal activity in cortical cells (Timofeev et al. 2002). Their role in PPN activity is unknown, so that future studies will require determination of changes in immunoreactivity of the various subunits across age in the PPN. We speculate that the increase in the proportion of cells showing $I_{\mathrm{h}}$ around 15 days compared with lower proportions before and after that time, may indicate an increase in expression, perhaps mediated by increased PPN cell activity.

Significantly, noradrenergic and serotonergic inputs can modulate thalamic (Pape and McCormick 1989) and hippocampal (Poolos et al. 2002) h-channels. PPN neurons also 
receive noradrenergic and serotonergic inputs. We have found that during the developmental decrease in REM sleep, serotonergic type 1 agonists induced less hyperpolarization early (12-13 days) than later (20-21 days) (Kobayashi et al. 2003). On the other hand, serotonergic type 2 agonists hyperpolarized a minority of cholinergic PPN neurons and only marginally in those affected, whereas hyperpolarizing most noncholinergic neurons significantly (Kobayashi et al. 2004). However, these effects did not change during the developmental decrease in REM sleep. This suggests that serotonergic type 1 receptors exercise a gradually increasing inhibition on PPN firing during the developmental decrease in REM sleep, but serotonergic type 2 receptors may not be related to this event. Preliminary results showed that the noradrenergic alpha-2 receptor agonist clonidine had the opposite effect on developing PPN neurons, inducing more hyperpolarization early than late during this period in development (K. Mamiya, R. D. Skinner, and E. Garcia-Rill, unpublished data). It is clear, however, that noradrenergic and serotonergic inputs to cholinergic PPN neurons do not show a transient effect around 15 days, rather a gradually increasing or decreasing effect over the period tested (12 through 21 days).

A comparison of Figs. 2 and $5 B$ reveals that cell size and the proportion of cells with Ih appear to change in parallel, in an inverted-U pattern (not gradually increasing or decreasing) peaking $\sim 15$ days. Moreover, the presence of $I_{\mathrm{h}}$ expectedly led to higher firing frequencies being induced in $I_{\mathrm{h}}$-positive cells after depolarizing pulses (compared with $I_{\mathrm{h}}$-negative cells). These factors suggest that $I_{\mathrm{h}}$ may contribute to increased levels of activity in PPN neurons, especially around the peak of the hypertrophy around 15 days. All of these factors lend support to the suggestion that it is PPN output, specifically cholinergic output, that is increasing transiently $\sim 15$ days. This hypothesis should be testable by determining if there is increased release of acetylcholine in the thalamus at $\sim 15$ days compared with before or after that time.

\section{Clinical implications}

We proposed that if the developmental decrease in REM drive does not occur, lifelong increases in REM sleep drive may ensue (Garcia-Rill et al. 2003). Could dysregulation of any of the developmental changes described herein be responsible for inducing increases in REM sleep drive? We suspect that the gradually in creasing or decreasing changes observed in AP and AHP duration during the 12- to 21-day period may not influence REM sleep drive to a significant extent. On the other hand, the hypertrophy and increases in percent of cells with $I_{\mathrm{h}}$ observed, which we suspect is related to a transient increase in PPN output at $\sim 15$ days, could lead to changes in REM sleep drive, particularly if such an effect is reinstated later in life due to pathological processes. Such an event would increase activity-dependent transcriptional factors such as the expression, or overexpression, of proteins like HCNs. This could lead to increased bursting or even paroxysmal activity. PPN cells are known to burst during REM sleep, but then only some types of PGO wave-related cells burst, whereas most PPN cells fire tonically especially during the steady REM sleep state (Steriade et al. 1990b). Only a small percentage of PPN cells actually generate such bursting, and then only in relation to PGO waves, perhaps influencing distant sites known to generate PGO waves (Datta 1997; Datta et al. 1998).

In schizophrenia, anxiety disorders, and bipolar and unipolar depression, increased REM sleep drive (increased REM duration, decreased REM latency, hypervigilance, etc., usually coupled with decreases in slow wave sleep) is a major, incapacitating symptom (Garcia-Rill 1997, 2002). One plausible idea is that this effect represents a regression to a previous developmental state. Interestingly, most patients with schizophrenia, bipolar depression, male obsessive-compulsive disorder (OCD), and panic attacks develop the disorder postpubertally [ $\sim 80 \%$ between the ages of 15 and 25 , during the normal decrease in REM sleep shown in humans (Roffwarg et al. 1966)], whereas unipolar depression in adolescents is very high (Garcia-Rill 1997). Interestingly, $\sim 80 \%$ of narcoleptic patients also have a postpubertal age of onset. Narcolepsy is characterized by sudden shifts into unconsciousness and atonia as if these were arousal-triggered episodes of REM sleep. However, we should note that other disorders that are not postpubertal in origin, such as Parkinson's, Huntington's and Alzheimer's diseases, all show increased REM sleep drive, along with anxiety-like deficits in sensory gating and "hypofrontality" (Garcia-Rill 1997, 2002). One group reported that neonates and endogenous depressives have the same distinctive features of baseline REM sleep (Vogel et al. 2000) and suggested that the REM sleep abnormalities of endogenous depression represent an immature, underdeveloped REM sleep system (Vogel et al. 1997).

It may be possible that the increased REM sleep drive in these disorders represents a regression to a developmental REM sleep state such as that seen soon after birth and may correspond to similar changes in firing that are evident $\sim 15$ days in the rat. Much additional evidence will be necessary to test this hypothesis. Animal models of disorders that manifest increased REM sleep drive (e.g., models of schizophrenia, depression, or anxiety disorder) would be expected to show increased PPN activity [we were the first to propose that the PPN was overactive in schizophrenia (Karson et al. 1991) and in Parkinson's disease (Teo et al. 1997)], increased proportions of cells with $I_{\mathrm{h}}$, increased HCN expression, and/or increased acetylcholine release in the thalamus, coupled with decreased release in frontal cortex (i.e., hypofrontality). Different disorders may manifest differential changes in each of these factors among others. Although these are speculative considerations, the basic normative information provided herein regarding the development of morphological and electrophysiological properties of PPN cells is absolutely essential for the future study of dysregulation of this system.

\section{Evolutionary considerations}

One question that should be addressed is if the human newborn spends $50 \%$ of total sleep time or $33 \%$ of the day in REM sleep and the rat newborn spends $>90 \%$ of total sleep time or $70 \%$ of the day in REM sleep, why is there such a large difference between the two species? Basically, in the human, the decrease in REM sleep becomes a gain in waking time with little change in slow-wave sleep duration. In the rat, the decrease in REM sleep becomes a gain for slow-wave sleep with no change in waking time. The suggestion has been made that, from an evolutiuonary perspective, the more evolved the spe- 
cies, the more waking time (reviewed in Garcia-Rill 2002). In ontogeny, there is a developmental increase in waking time in the human (Roffwarg et al. 1966), which mirrors a phylogenetic increase in waking in higher species. In the rat, there is no net gain in waking time in ontogeny (Jouvet-Mounier et al. 1970) as waking duration remains at the same proportion of the day in the adult. We suspect that the critical factor in evolution is not REM sleep duration but waking time duration. Once the developmental role of REM sleep has been served, it may be that it is shed in favor of the most advantageous other state, be it waking in the human or slow-wave sleep in the rat. However, it is this interesting, transient developmental role of REM sleep, and the disturbed development of which could have such dire consequences, that our efforts address.

\section{G R A N T S}

This work was supported by National Institute of Neurological Disorders and Stroke Grant NS-20246 and National Science Foundation Award IBN0237314

\section{REFEREN CES}

Bender RA, Brewster A, Santoro B, Ludwig A, Hofmann F, Biel M, and Baram TZ. Differential and age-dependent expression of hyperpolarizationactivated, cyclic nucleotide-gated cation channel isoforms 1-4 suggests evolving roles in the developing hippocampus. Neuroscience 106: 689-698, 2001.

Brewster A, Bender RA, Chen Y, Dube C, Eghbal-Ahmadi M, and Baram TZ. Developmental febrile seizures modulate hippocampal gene expression of hyperpolarization-activated channels in an isoform- and cell-specific manner. J Neurosci 22: 4591-4599, 2002.

Chevaleyre V and Castillo PE. Assessing the role of $I_{\mathrm{h}}$ channels in synaptic transmission and mossy fiber LTP. Proc Nat Acad Sci USA 99: 9538-9543, 2002.

Datta S. Neuronal activity in the peribrachial area: relationship to behavioral state control. Neurosci Biobehav Rev 19: 67-84, 1995.

Datta S. Cellular basis of pontine ponto-geniculo-occipital wave generation and modulation. Cell Mol Neurobiol 17: 341-365, 1997.

Datta S. Evidence that REM sleep is controlled by the activation of brain stem pedunculopontine tegmental kainate receptor. J Neurophysiol 87: 1790$1798,2002$.

Datta S and Siwek DF. Single cell activity patterns of pedunculopontine tegmentum neurons across the sleep-wake cycle in the freely moving rats. J Neurosci Res 70: 611-621, 2002.

Datta S, Siwek DF, Patterson EH, and Cipolloni PB. Localization of pontine PGO wave generation sites and their anatomical projections in the rat. Synapse 30: 409-423, 1998.

DiFrancesco D. Pacemaker mechanisms in cardiac tissue. Ann Rev Physiol 55: 455-472, 1993.

Garcia-Rill E. Disorders of the reticular activating system. Med Hypoth 49: 379-387, 1997.

Garcia-Rill, E. Mechanisms of sleep and wakefulness. In: Sleep Medicine, edited by Lee-Chiong T, Sateia MJ, and Carskadon MA. Philadelphia, PA: Hanley and Belfus, 2002, p. 31-39.

Garcia-Rill E, Kobayashi T, and Good C. The developmental decrease in REM sleep. Thal Related Syst 2: 115-131, 2003.

Jouvet-Mounier D, Astic L, and Lacote D. Ontogenesis of the states of sleep in rat, cat, and guinea pig during the first postnatal month. Dev Psychobiol 2: $216-239,1970$.

Kamondi A, Williams J, Hutcheon B, and Reiner P. Membrane properties of mesopontine cholinergic neurons studied with the whole cell patch-clamp technique: implications for behavioral state control. J Neurophysiol 68: 1359-1372, 1992.

Kang Y and Kitai ST. Electrophysiological properties of pedunculopontine neurons and their postsynaptic responses following stimulation of substantia nigra reticulata. Brain Res 535: 79-95, 1990.

Karson CN, Garcia-Rill E, Biedermann JA, Mrak RE, Husain M, and Skinner RD. The brain stem reticular formation in schizophrenia. Psychiatry Res 40: 31-48, 1991.
Kobayashi T, Homma Y, Good C, Skinner RD, and Garcia-Rill E. Developmental changes in the effects of serotonin on neurons in the region of the pedunculopontine nucleus. Dev Brain Res 140: 57-66, 2003.

Kobayashi T, Good C, Mamiya K, Skinner RD, and Garcia-Rill E. Development of REM sleep drive and clinical implications. J App Physiol In press.

Kungel M, Koch M, and Friauf E. Cysteamine impairs the development of acoustic startle response in rats: possible role of somatostatin. Neurosci Lett 202: 181-184, 1996.

Leresche N, Lightowler S, Soltesz I, Jassik-Gerschenfeld D, and Crunelli V. Low-frequency oscillatory activities intrinsic to rat and cat thalamocortical cells. J Physiol 441: 155-174, 1991.

Leonard CS and Llinas RR. Electrophysiology of mammalian pedunculopontine and laterodorsal tegmental neurons in vitro:implications for the control of REM sleep. In: Brain Cholinergic Systems, edited by Steriade M and Biesold D. Oxford, UK: Oxford Science, 1990, p. 205-223.

Llinas R. Possible role of tremor in the organization of the nervous system. In: International Neurological Symposium on Tremor, edited by Findley LJ and Capildeo R. London, UK: MacMillan, 1984, p. 473-478, 1984.

Luthi A, Bal T, and McCormick DA. Periodicity of thalamic spindle waves is abolished by ZD7288, a blocker of Ih. J Neurophysiol 79: 3284-3289, 1998.

Marks GA, Shaffery JP, Oksenberg A, Speciale SG, and Roffwarg HP. A functional role for REM sleep in brain maturation. Behav Brain Res 69: 1-11, 1995.

McCormick DA and Pape HC. Properties of a hyperpolarization-activated cation current and its role in rhythmic oscillation in thalamic relay neurons. J Physiol 431: 291-318, 1990.

Ninomiya Y, Koyama Y, and Kayama Y. Postnatal development of choline acetyltransferase activity in the rat laterodorsal tegmental nucleus. Neurosci Lett 308: 138-140, 2001.

Pape HC and McCormick DA. Noradrenaline and serotonin selectively modulate thalamic burst firing by enhancing a hyperpolarization-activated cation current. Nature 340: 715-718, 1989.

Petersson P, Waldenstrom A, Fahraeus C, and Schouenborg J. Spontaneous muscle twitches during sleep guide spinal self-organization. Nature 424: 72-75, 2003.

Poolos NP, Migliore M, and Johnston D. Pharmacological upregulation of h-channels reduces the excitability of pyramidal neuron dendrites. Nature Neurosci 5: 767-774, 2002.

Roffwarg HP, Muzio JN, and Dement WC. Ontogenetic development of the human sleep-dream cycle. Science 152: 604-619, 1966.

Sakai K, El Mansari M, and Jouvet M. Inhibition by carbachol microinjections of presumptive cholinergic PGO-on neurons in freely moving cats. Brain Res 527: 213-223, 1990.

Santoro B and Baram TZ. The multiple personalities of h-channels. Trends Neurosci 26: 550-554, 2003.

Sheets LP, Dean KF, and Reiter LW. Ontogeny of the acoustic startle response and sensitization to background noise in the rat. Behav Neurosci 102: 706-713, 1988.

Shimizu N and Imamoto K. Fine structure of the locus coeruleus in the rat. Arch Histol Jpn 31: 229-246, 1970.

Sievers J, Lolova I, Jenner S, Klemm HP, and Sievers H. Morphological and biochemical studies on the ontogenesis of the nucleus locus coeruleus. Bibl Anat 19: 52-130, 1981.

Skinner RD, Conrad N, Henderson V, Gilmore S, and Garcia-Rill E. Development of NADPH diaphorase positive pedunculopontine neurons. Exp Neurol 104: 15-21, 1989.

Soltesz I, Lightowler S, Leresche N, Jassik-Gerschenfeld D, Pollard C, and Crunelli V. Two inward currents and their transformation of low-frequency oscillations of rat and cat thalamo-cortical cells. J Physiol 441: 175-197, 1991.

Spann BM and Grofova I. Cholinergic and non-cholinergic neurons in the rat pedunculopontine tegmental nucleus. Anat Embryol 186: 215-227, 1992.

Steriade M, Amzica F, and Contreras D. Synchronization of fast $(30-40$ $\mathrm{Hz}$ ) spontaneous cortical rhythms during brain activation. J Neurosci 16: 392-417, 1996.

Steriade M, Datta S, Pare D, Oakson G, and Curro Dossi R. Neuronal activities in brain-stem cholinergic nuclei related to tonic activation processes in thalamocortical systems. J Neurosci 10: 2541-2559, 1990 b.

Steriade M, Paré D, Datta S, Oakson G, and Curro Dossi R. Different 
cellular types in mesopontine cholinergic nuclei related to ponto-geniculooccipital waves. J Neurosci 10: 2560-2579, 1990a.

Steriade M, Timofeev I, and Grenier F. Natural waking and sleep states: a view from inside neocortical neurons. J Neurophysiol 85: 1969-1985, 2001.

Takakusaki K and Kitai ST. Ionic mechanisms involved in the spontaneous firing of tegmental pedunculopontine nucleus neurons of the rat. Neuroscience 78: 771-794, 1997.

Takakusaki K, Shiroyama T, Yamamoto T, and Kitai ST. Cholinergic and noncholinergic tegmental pedunculopontine projection neurons in rats revealed by intracellular labeling. J Comp Neurol 371: 345-361, 1996.

Takakusaki K, Shiroyame T, and Kitai ST. Two types of cholinergic neurons in the rat tegmental pedunculopontine nucleus:electrophysiological and morphological characterization. Neuroscience 79: 1089-1109, 1997.

Teo C, Rasco L, Al-Mefty K, Skinner RD, and Garcia-Rill E. Decreased habituation of midlatency auditory evoked responses in Parkinson's disease. Movement Dis 12: 655-664, 1997.
Timofeev I, Bazhenov M, Seinowski T, and Steriade M. Cortical hyperpolarization-activated depolarizing current takes part in the generation of focal paroxysmal activities. Proc Nat Acad Sci USA 99: 9533-9537, 2002.

Vasilyev DV and Barish ME. Postnatal development of the hyperpolarization-activated excitatory current Ih in mouse hippocampal pyramidal neurons. J Neurosci 22: 8992-9004, 2002.

Vincent SR, Satoh K, Armstrong D, and Fibiger H. NADPH-diaphorase: a selective histochemical marker for the cholinergic neurons in the pontine reticular formation. Neurosci Lett 43: 31-36, 1983.

Vogel GW, Feng P, and Kinney GG. Similar REM sleep characteristics in neonates and in endogenous depressives. Sleep Res. 26: 170-178, 1997.

Vogel GW, Feng P, and Kinney GG. Ontogeny of REM sleep in rats: possible implications for endogenous depression. Physiol Behav 68: 453$461,2000$. 